\title{
Fabric-Based Computing: (Re)examining the Materiality of Computer Science Learning Through Fiber Crafts
}

\author{
Anna Keune ${ }^{1}$ D \\ Received: 21 September 2021 / Accepted: 25 November 2021 / Published online: 7 December 2021 \\ (c) The Author(s) 2021
}

\begin{abstract}
Fiber crafts, such as weaving and sewing, occupy a tension-filled space within computing. While associated with domestic practices, fiber crafts have been recognized as a precursor of the earliest computers and continue to present sources of computational inspiration. The connections between fiber crafts and computing have the potential to uncover possibilities for computing to become more diversified in terms of materials, cultural practices, and ultimately people. To explore the promises of fiber crafts for STEM education, this qualitative dissertation built on constructionist and posthumanist perspectives to examine two fiber crafts (i.e., weaving and fabric manipulation) as contexts for computer science learning. Collectively, the dissertation effectively aligned fiber crafts with computational concepts and showed their potential as a promising context for computer science learning. The work further showed that materials used for STEM learning are non-neutral. Materials matter in what can be learned computationally. Lastly, guided by posthumanist perspectives, the dissertation uncovered computational learning as the process of producing physical expansions and highlighted learning as the process of how computational concepts physically change. The work has implications for theorizing learning, designing for learning, and educational practice. For example, the dissertation presents the utility of posthumanist perspectives as an additional theoretical approach to the study of learning that can surface and help address ongoing relational deficit orientations.
\end{abstract}

Keywords Fiber crafts $\cdot$ Computational concepts $\cdot$ Posthumanist perspectives $\cdot$ Constructionism $\cdot$ Materiality of learning

\section{Introduction}

Amid the hustle and buzzle of a middle school classroom, eight students sat quietly at a craft table, warp threads stretched across their yarn-filled workspace. As heddles turned and busy hands flew shuttles across warp threads, a song emerged from a young crafter, Asher (pseudonym), mirroring the if this then that rhythm of weaving: "You've got to twist it and turn it and push it and pull it." A few weeks later, the young crafters rejoined the craft table. This time, fabric, thread, and needle cushions were scattered about. One of the crafters, Savanna, sewed together a grid of four dots that she had penciled on top of brightly colored

Anna Keune

anna.keune@tum.de

1 Department of Educational Sciences, School of Social Sciences and Technology, Technical University of Munich, Munich, Germany fabric. Vigilantly, she picked up one dot at a time with her needle, connecting a total of four dots with a thin thread before pulling all the dots together. As the fabric ruffled, it revealed a flat-folding square. Savanna began to sew another square and explained: "It's like a programming loop." All eyes turned to Savanna.

Moments of capricious crafting, in which materials seemed to do more than serve the purpose of human designers, was what this research set out to investigate as computational learning. The dissertation explored fiber crafts for computational learning from the vantage point of several studies to better understand the active roles materials play in learning. The research focused on fiber crafts because they occupy a tension-filled space within computing. On the one hand, the domestic associations of fiber crafts have been utilized to prevent women and other non-dominant populations from entering Science, Technology, Engineering, and Mathematics (STEM) fields (e.g., Barber [2]). On the other hand, fiber crafts-particularly weaving — have been recognized for their connections with computation (e.g., Essinger [5], Harlizius-Klück [8]) and as a precursor of the earliest 
computers with the Jacquard loom (e.g., Plant [14]). Today, fiber crafts still present sources of inspiration for the future of computing (e.g., Fernaeus et al. [6]). Leah Buechley's [4] foundational work on electronic textiles showed how fiber crafts can be a source for widening computational cultures (see also Buchholz et al. [3], Kafai et al. [9], Pinkard et al. [13]). To investigate the active role of materials in learning, fiber crafts served as context for computation from the perspective of computing experts and from the perspective of youth crafters.

Building on prior work that identified fiber crafts as a promising context for mathematics learning (e.g., Peppler et al. [12]), this qualitative research is rooted in constructionist traditions [11]. Constructionism posits that learning happens best when learners manipulate tangible materials toward the design of personally meaningful and shareable projects and, in the process, explore the inherent disciplinary concepts these materials contain [11]. The study infuses constructionist approaches with post-humanist perspectives to guide the investigation into the role materials play in computational learning. Building on the findings of indigenous scholars, physicists, and gender scholars, post-humanist perspectives radically question the role of materials as mediators, which underpins much of contemporary learning theory (e.g., Barad [1], Kuby [10], Rosiek et al. [15]). For example, by decentering humans, post-humanist perspectives guide researchers to analyze how materialized patterns and routines produce and reproduce class-, gender-, race-, and ethnicity-related deficit orientations (e.g., Thiel and Jones [16]). Departing from deeply rooted conceptions that determine what can be seen and supported as learning allows a renewed look at educational challenges with the potential to uncover ongoing learning processes that may otherwise remain overlooked. This shift in perspective can reveal new theoretical and methodological insights into an equity-oriented study of learning. To produce theoretical intersections, the dissertation moved from a sole constructionist approach in the first finding chapter to a dual theoretical approach in the second findings chapter, to a predominantly posthumanist approach in the third findings chapter.

The dual theoretical approach had methodological implications as the data collection and data analysis had to be aligned with the theoretical orientation. To investigate the active role of materials in learning, fiber crafts were illuminated as material context for computational learning. First, artifact analyses with computer science experts explored computational concepts (e.g., loops, variables) in fiber crafts to establish the crafts as contexts for learning. Second, video analysis of middle-school craft courses investigated how youth and fiber crafts performed computational concepts. Third, the analysis of repetitions and variations in the middle school crafts could serve to analyze the way materials drove computing. Synthesizing across the contributions of the individual chapters of the dissertation, the dissertation contributes to research that shows that materials are nonneutral drivers of learning. Taking creative materials that are not typically found in computing seriously as computational contexts can expand approaches to teaching, decrease deficit thinking, and widen computing cultures. The work presents implications for theorizing learning as emergent from within human-materials relationships and provides insights into how posthumanist perspectives are compelling for illuminating constructionist theoretical approaches to learning.

\section{Research Questions}

With the aim to better understand the materiality of learning in the context of fiber crafts and computing, the work investigated three interconnected research questions:

- How do weaving and manipulating fabric support engagement with computational concepts?

- What computational concepts do youth produce while weaving and manipulating fabric?

- How do the material-discursive practices of weaving and manipulating fabric drive computation?

\section{Studying Computational Learning in Fiber Crafts}

This research took a qualitative methodological approach to address the research questions. Table 1 presents an overview of the methods.

One of the analytical techniques that this dissertation advanced within educational research is to translate fiber crafts projects into pseudocode. The technique was inspired by the prior work by the author and colleagues of translating fiber crafts into mathematics and by work that has translated weaving into the Scheme programming language (e.g., Griffiths and McLean [7]). Using pseudocode translation as part of an artifact analysis within educational context presents a novel analytical technique also for comparing domain conceptual changes in youth projects over time and inspired future methodological directions of this work.

\section{An Overview of the Dissertation Findings}

The dissertation contributes to the conceptualization of fabric-based computing and an improved understanding of the role materials can play in learning. The findings of the dissertation show that fiber crafts can be a promising context for computer science education. Specifically, the findings show how weaving and manipulating fabric 
Table 1 High level overview of research methods

\begin{tabular}{|c|c|c|}
\hline Research question & Data sources & Analytical techniques \\
\hline $\begin{array}{l}\text { How do weaving and manipulating fabric } \\
\text { support engagement with computational } \\
\text { concepts? }\end{array}$ & $\begin{array}{l}\text { Interviews and artifact analysis sessions with } \\
12 \text { computer science instructors } \\
\text { Youth created fiber crafts projects }\end{array}$ & $\begin{array}{l}\text { Interviews and artifact analysis sessions with } \\
12 \text { computer science instructors } \\
\text { Youth created fiber crafts projects }\end{array}$ \\
\hline $\begin{array}{l}\text { What computational concepts do youth } \\
\text { produce while weaving and manipulating } \\
\text { fabric? }\end{array}$ & $\begin{array}{l}\text { Video assemblage of } 6 \text {-session long fiber } \\
\text { crafts courses with middle schoolers }(\mathrm{n}= \\
16 ; 8 \text { females, } 8 \text { males }) \\
\text { Semi-structured interviews } \\
\text { Close-up project documentation }\end{array}$ & $\begin{array}{l}\text { Videos: content logs to track material design } \\
\text { processes } \\
\text { Interviews: tracking material processes required } \\
\text { for crafts } \\
\text { Projects: reverse-engineering projects; Python- } \\
\text { inspired pseudocode translations }\end{array}$ \\
\hline $\begin{array}{l}\text { How do the material-discursive practices } \\
\text { of weaving and manipulating fabric drive } \\
\text { computation? }\end{array}$ & $\begin{array}{l}\text { Video of fiber crafts courses from different } \\
\text { perspectives: eye-level, birds-eye-view, } \\
\text { close-up project videos }\end{array}$ & $\begin{array}{l}\text { Iterative coding of videos for repetitions and } \\
\text { variations in youth-material combinations } \\
\text { during computationally relevant moments }\end{array}$ \\
\hline
\end{tabular}

call for the performance of computational concepts (i.e., algorithms, variables, control structures, modularity, and troubleshooting).

For example, control structures refer to a program's flow, the role of each part, and how parts are connected. This includes sub-concepts such as computational loops, which repeat a set of instructions until a particular state is reached. One example of control structures in fiber crafts is detectable by zooming in on students' woven projects and its translation into pseudocode. Kara and Lionel's fabric (Fig. 1) shows an example of youth manually repeating loops across their fabric. The pseudocode presents the conditional states of the loom's heddle in motion (i.e., how the parts of the loom with long and short openings for lifting threads moved up and down): if the heddle was pulled up (i.e., if heddle $==1$ ), youth woven from the left to the right and if the heddle was drawn down (i.e., if heddle $==-1$ ), youth woven from the right to the left. Instructors said that the heddle movements provided a physical sense of how computers process data.
The dissertation provides additional examples of the alignment between both fiber crafts and computational concepts in greater depth.

To provide a snapshot of other findings of the dissertation, I highlight here findings that derived from combining constructionist approaches to learning (e.g., Papert [11]) with a posthumanist lens (e.g., Barad [1]) to guide the analysis of how repetition of component combinations changed and what this meant for computational learning. Two interesting phenomena became visible: First, when middle school youth and crafts produced computational concepts, computational learning looked very different across the crafts. Materials shaped what could be learned computationally. This posits the importance of more than one material for computational learning that is aimed toward computational diversity. Second, when relationships of people and craft materials diverged from the typical repeating series, computing physically expanded. From this vantage point, computational learning was the process of expanding what
Fig. 1 Kara and Lionel's fabric and the researcher's pseudocode translation of the first three rows of the project

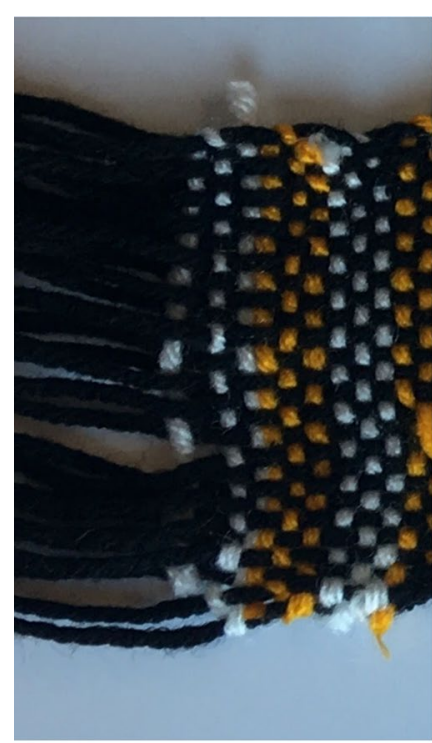

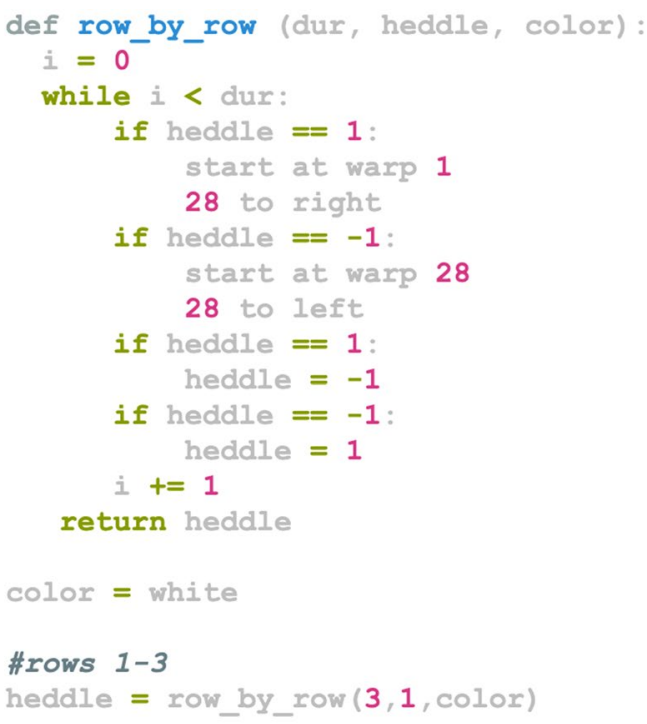


human-craft relationships were physically part of what could be recognized as computational. Posthumanist perspectives suggest that to capture learning we need to compare changes that happen within physical instantiations of a phenomena in addition to focusing on changes to the person in relation to external standards.

\section{Implications}

The research (re)examines the role of materials in computer science learning. Collectively, the work presents fiber crafts as a context for computing, in which craft materials take part in what is learned and experienced computationally. Further, the work contributes to an enriched understanding of the materiality of computer science learning, one in which materials are non-neutral. The research shows that taking on posthumanist perspectives can open avenues for new lines of theory-driven education inquiry that can advance commitments to STEM equity.

Funding Open Access funding enabled and organized by Projekt DEAL. This work was supported by the Anita Borg Institute.

Availability of data and material Data can be made available upon request.

Code availability None.

\section{Declarations}

Conflicts of interest No conflict of interest exists.

Ethics approval The study was approved by the institutional review board (IRB) of Indiana University.

Open Access This article is licensed under a Creative Commons Attribution 4.0 International License, which permits use, sharing, adaptation, distribution and reproduction in any medium or format, as long as you give appropriate credit to the original author(s) and the source, provide a link to the Creative Commons licence, and indicate if changes were made. The images or other third party material in this article are included in the article's Creative Commons licence, unless indicated otherwise in a credit line to the material. If material is not included in the article's Creative Commons licence and your intended use is not permitted by statutory regulation or exceeds the permitted use, you will need to obtain permission directly from the copyright holder. To view a copy of this licence, visit http://creativecommons.org/licenses/by/4.0/.

\section{References}

1. Barad K (2003) Posthumanist performativity: toward an understanding of how matter comes to matter. Signs J Women Cult Soc 28(3):801-831

2. Barber EW (1995) Women's work: the first 20,000 years women, cloth, and society in early times. WW Norton \& Company, New York

3. Buchholz B, Shively K, Peppler K, Wohlwend K (2014) Hands on, hands off: gendered access in crafting and electronics practices. Mind, Cult Act 21(4):278-297

4. Buechley L (2006) A construction kit for electronic textiles. In: Wearable computers, 2006 10th IEEE international symposium. IEEE, pp 83-90

5. Essinger J (2004) Jacquard's web: how a hand-loom led to the birth of the information age. Oxford University Press, Cambridge

6. Fernaeus Y, Jonsson M, Tholander J (2012) Revisiting the Jacquard loom: threads of history and current patterns in HCI. In: Proceedings of the SIGCHI conference on human factors in computing systems. ACM, pp 1593-1602

7. Griffiths D, McLean A (2017) Textility of code: a catalogue of errors. Textile 15(2):198-214

8. Harlizius-Klück E (2017) Weaving as binary art and the algebra of patterns. Text Cloth Cult 15(2):176-197

9. Kafai Y, Fields D, Searle K (2014) Electronic textiles as disruptive designs: supporting and challenging maker activities in schools. Harv Educ Rev 84(4):532-556

10. Kuby CR (2017) Why a paradigm shift of 'more than human ontologies' is needed: putting to work poststructural and posthuman theories in writers' studio. Int J Qual Stud Educ 30(9):877-896

11. Papert S (1980) Mindstorms: children, computers, and powerful ideas. Basic Books, New York

12. Peppler K, Keune A, Bender S (under review) Math across crafts: fiber crafts as new tangible manipulatives for proportional reasoning

13. Pinkard N, Erete S, Martin CK, de McKinney M (2017) Digital youth divas: exploring narrative-driven curriculum to spark middle school girls' interest in computational activities. J Learn Sci 26(3):477-516

14. Plant $S$ (1995) The future looms: weaving women and cybernetics. Body Soc 1(3-4):45-64

15. Rosiek JL, Snyder J, Pratt SL (2020) The new materialisms and Indigenous theories of non-human agency: Making the case for respectful anti-colonial engagement. Qual Inq 26(3-4):331-346

16. Thiel JJ, Jones S (2017) The literacies of things: reconfiguring the material-discursive production of race and class in an informal learning centre. J Early Childh Lit 17(3):315-335

Publisher's Note Springer Nature remains neutral with regard to jurisdictional claims in published maps and institutional affiliations. 